http://www.jfas.info

\title{
SOURCE APPORTIONMENT OF SOCIAL SUPPORT AND QUALITY OF LIFE INDEX AMONG DRUG ABUSE INMATES USING MULTIPLE LINEAR REGRESSION
}

N. A. M. Ali ${ }^{1}$, M. Mohamad ${ }^{1, *}$, H. Juahir ${ }^{2}$, M. K. A. Kamarudin ${ }^{2}$, N. Muhammad ${ }^{1}$ and M. S. M. R. Lee ${ }^{1}$

${ }^{1}$ Faculty of Economics and Management Sciences, Universiti Sultan Zainal Abidin, Gong Badak Campus, 21300 Kuala Nerus, Terengganu, Malaysia

${ }^{2}$ East Coast Environmental Research Institute (ESERI), Universiti Sultan Zainal Abidin, Gong Badak Campus, 21300 Kuala Nerus, Terengganu, Malaysia

Published online: 08 August 2017

\begin{abstract}
Drug addictions are some of the contributing factors to low level of quality of life (QoL) and other psychological problems in individuals. Studies on the influence of social support on the QoL of inmates with drug abuse dependency have identified that inmates who maintain close contact with their family and friends associated themselves with better satisfaction in interpersonal relationships. This study intends to show the effectiveness of Factor Analysis (FA) and Multiple Linear Regression (MLR) for the assessing quality of life indicator sources. The data from 12 prisons selected in Peninsular Malaysia was collected during the period April and June 2015. The 1753 respondents were selected using simple random sampling. The method of FA has identified five significant index categories- Excellent, Good, Moderate, Low and poor quality of life index (QoLi) were generated from FA.
\end{abstract}

Keywords: social support; quality of life; multiple linear regression; inmates; factor analysis.

Author Correspondence, e-mail: mahadzirahmd@unisza.edu.my doi: http://dx.doi.org/10.4314/jfas.v9i2s.4 


\section{INTRODUCTION}

\subsection{Prison Population}

Prison population was reported to be a marginalized group within a society. Importantly, the increasing in total prison population one of the primary problems not only in Malaysia (Fig. 1), unfortunately it is a worldwide problem as more than 10.2 million inmates are held in prison throughout the world. It is known that the number of user is disproportionately high in prison. Worldwide estimation reported the count of injecting drug users are nearly to $90 \%$ will be incarcerated [1].

In Malaysia, the prison population is increasing from year 2000 (27,358 total) to 2015 (51,946 total). From the total population, 30,000 of sentenced inmates having drug-related offenses [2] and surprisingly that almost $97 \%$ of the imprisoned drugs addicts are male [3]. Drug addictions are some of the contributing factors to low level of quality of life and other psychological problems in individuals. Moreover, the illicit drug usage contributing effects on not only health lives of individuals, but it also considered such of significant social illnesses such as high risk sexual behavior [4], public health and safety threat in Malaysia [5].

Despite various ways has been made by the government to solve drug-associated problems in order striving for a visionary of drug-free society in 2015 [6], this drug related problem has remained constant and 2015 visionary yet to be achieved. This issue had alleviated government worries upon increases in the percentage of drug addicts despite the implementation of numerous prevention and treatment and rehabilitation programs, especially in prison institution [7].

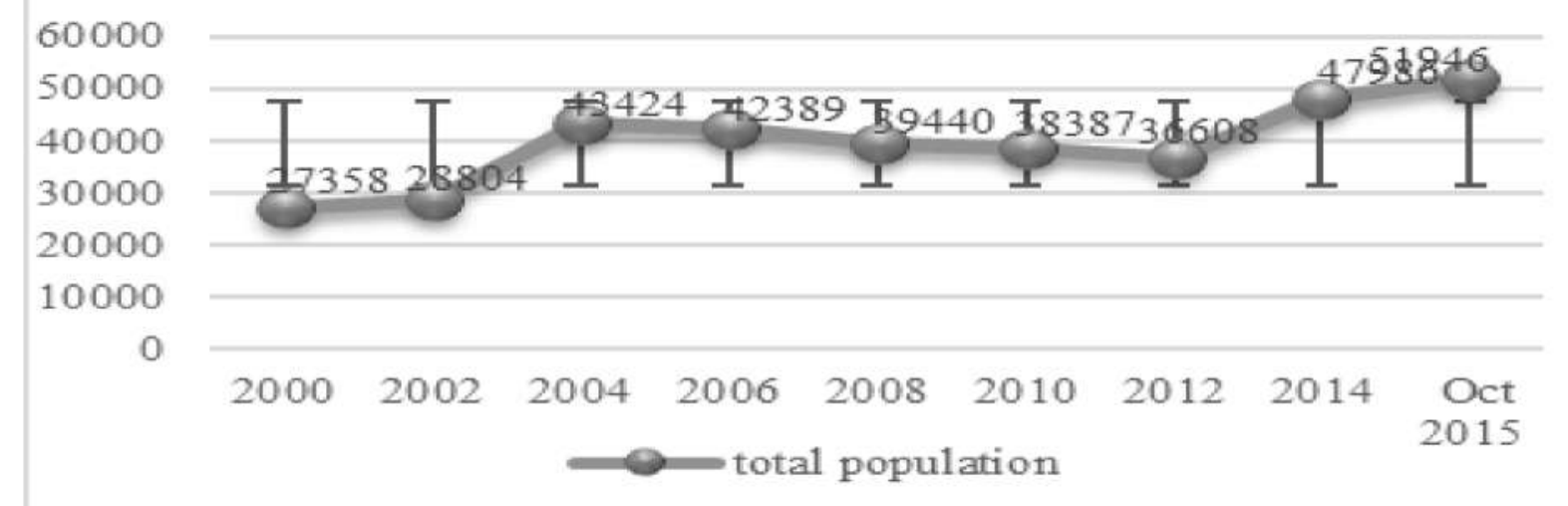

Fig.1. The Malaysian prison population 
In order to tackle the problem, the subjective intervention such as social support is important for imprisoned drug abuse to cope with the challenges of life [8] and reintegrate with the community. Studies on the influence of social support on the quality of life (QoL) of inmates with drug abuse dependency have identified the fact that inmates who maintain close contact with their family and friends associated themselves with better satisfaction in interpersonal relationships [9]. In this context, social support comprises support from family, friends and significant others (prison officers, Non-Governmental Organizations (NGOs) and Government) plays important variables in the QoL of the inmates and the drug abuser to return to their normal life [10].

This study is to identify the potential sources of variations in social support among drug abuse inmates around the study area. Identification of the sources of social support, especially among drug abuse inmates, is important. The source apportionment analysis to determine the category of index in quality of life, particularly in prison context. Previous study by [11] using multivariate analysis (Segmentation and Cluster Analysis) to explore the characteristics of the customers and their quality perception. In this study, Factor analysis (FA) in combination with multiple linear regression (MLR) has been chosen to determine the source apportionment of social support and quality of life index studies. Meanwhile, MLR is applied to explain the dependent variables as it allows formation of explicit equations that are less complex [12].

\subsection{Social Support and QoL Outcome}

Social support may be described as having a family and a network of close friends who provide social and emotional attachment for all physical and emotional needs [13-14]. The family becomes the fundamental support of care for the inmates [15]. In incarcerated adolescent study by [16] found that family support is important in reducing antisocial behavior among those low in impulse control. Social support includes the structure of the social relationships network of connections with other human beings in order to address the need for social interaction [17] that can provide assistance, support and help for a person [18]. Moreover, social support includes features provided by others such as: 1) emotional, involving empathy to somebody who needs it such as expressions of love and affection, 2) instrumental, regarding to provision of material needs and material support such as goods and 
services that help solve practical problems [19], 3) which may be used to deal with problems and solving them; 4) and positive social interaction including the availability of people with whom one can have fun and relax from feelings of loneliness [20].

The social support is important factor of quality of life as it might lead to a reduction in (negative social) antisocial outcomes. The antisocial outcomes such as such as the inmate social system and its negativistic inmate code [21] may influencing a number of other related aspects of prison life including deaths in custody, the use of force towards prisoners and the occurrence of prison riots, disturbances and general disorder [22] as may act to decrease an inmate's probability of successful reentry into society [23].

Quality of life refers to people's life situations. The concept requires a micro perspective where the conditions and perceptions of individuals play a key role. In life, a person usually has to play a few roles in one time and these parts require a person to fulfill various needs simultaneously. The needs can be in form of individual, family, community member or society member [24].

\section{METHODOLOGY}

\subsection{Sample Collection}

The data from 12 prisons selected in Peninsular Malaysia was collected through interviews using a structured questionnaire during the period April and June 2015. Since these prisons are widely scattered in term of geographical location, the study applied area sampling method whereby the peninsular Malaysia is divided into 4 areas namely Eastern region, Northern Region, Southern Region and Central Region. The Eastern Region consist of Kelantan (Pengkalan Chepa) and Pahang (Bentong and Penor) prisons. The Northern region consists of Kedah (Pokok Sena and Sungai Petani) and Pulau Pinang (Seberang Perai) prisons. The Southern Region consists of Johor Bharu (Kluang and Simpang Renggam). Last, the Central region consist of Selangor (Kajang), Negeri Sembilan (Seremban and Jelebu) and Perak (Tapah) prisons. Once the prison is selected, using simple random sampling, the 1752 respondents are selected from the sampling frame provided by the prison authority using the random numbers generated through the SPSS [25]. 


\subsection{Social Support Measurement}

Social Support: The instrument to measure social support adapted from the Multidimensional Scale of Support (MSPSS) [26] consisting of 15 items. After conducting a pilot study, only 9 items in social support measuring three domains (family, friends and significant others) were used for the actual survey. The study uses questionnaires to collect data from the respondents. The measurement used 10-point scale ranging from 1 "strongly disagree" to 10 "strongly agree".

Quality of Life: The drug abuse inmates' QoL was assessed by the Maqasid Shariah Quality of Life (MSQoL) questionnaire which containing 80 questions, five dimension (religion, life, mind, lineage and property). This questionnaire is adopted from [24] derived from project "Developing a model Quality of Life Maqasid Shariah Approach" under NRGS grant RR057-3. The five dimension questions are calculated together to generate a single score, regardless of the other domain scores which is called the General Quality of Life Index (GQLI).

\subsection{Data Analysis}

A preliminary source identification of this study was carried out through FA-MLR using XLSTAT 2013 software version 3.1. In [27] explained that the primary objective in applying FA analysis is to develop a small number of components to explain the maximum variance possible in the dataset. Prior to analysis, the outlier values were eliminated [28]. All data were normalized using the appropriate procedure [27] and the number of principal components was decided based on eigenvalues $>1$ [29] on factor loading $(>0.75)$ was chosen for classification purposes [30].

\subsection{Factor Analysis (FA)}

FA is applied to identify the underlying dimensions of social support among drug abuse inmates. The FA were performed to infer relationships between variables [31-32]. Varimax method is used in the FA techniques. The varimax rotation guarantees that every items associated with only one principal component as encompassing a near-zero relationship with the other components [33]. Eigenvalues obtained from varimax rotation are the precursor of the FA. Eigenvalues over than 1 were significant and subsequently varimax factors (VFs), 
which are the new groups of variables are generated. The VFs values which are greater than $0.75(>0.75)$ is considered as "strong", the values range from $0.50-0.75(0.50 \geq$ factor loading $\geq 0.75)$ is considered as "moderate" and the values range from $0.30-0.49(0.30 \geq$ factor loading $\geq 0.49)$ is considered as "weak" factor loadings [30, 34].

In practice, only factor loadings with absolute values greater than 0.75 are selected for the principal component interpretation [35]. The fundamental model of FA is stated as Equation (1):

Z_(ij $=)$ a_(f1 ) f_(1i $)+a \_f 2 f \_2 i+\cdots+a \_f m f \_m i+e \_f i$

where $\mathrm{z}$ is the measured value of a variable, $\mathrm{a}$ is the factor loading, $\mathrm{f}$ is the factor score, $\mathrm{e}$ is representing the residual term accounting for errors or other sources of variation, $\mathrm{i}$ is the sample number, $\mathrm{j}$ is the variable number and $\mathrm{m}$ is the total number of factors.

In this study, orthogonal varimax rotation method is applied to ensure that the attributes are correlated maximally with one factor and for ease of interpreting the factors. The Anderson-Rubine method is carried in identifying the factor score coefficients in order to ensure that the factor scores are uncorrelated.

\subsection{Multiple Linear Regression (MLR)}

The Multiple linear regression is allowing us to predict the variability between the independent variable and the dependent variable, as well as to calculate the percentage of the contribution of each variable to the social support. To determine the social support contribution of the identified sources, the MLR statistical approach was then applied. In the linear regression model, social support values from FA were assigned as independent variables meanwhile QoLi were assigned as dependent variables. The coefficient value $\left(\mathrm{R}^{2}\right)$ in each factor was then used to calculate the apportionment of each source to the Quality of life index. In this study, the source of apportionment of social support (independent variable) was used to identify the potential of the total QoLi (dependent variable) in the study area. Due to the importance of $\mathrm{R}^{2}$, adjusted $\mathrm{R}^{2}$ and RMSE values for better coefficient results, the finding shows that the values of $\mathrm{R}^{2}$, adjusted $\mathrm{R}^{2}$ and RMSE for the social support variables-QoLi were $0.244,0.240$ and 0.160 respectively from the goodness of fit statistics. 


\section{RESULTS AND DISCUSSION}

\subsection{Source Identification Using Factor Analysis}

Factor analysis used to identify dominant source categories [35] and the results obtained by varimax rotated factor analysis for Quality of Life index (QoLi) are presented in Table 1. A factor loading of more than 0.6 and below 0.4 is described as strong and weak respectively. While a loading of between 0.4 and 0.6 is described as moderate [36]. The database consists of nine social support variables and the quality of life index. The estimation of the factor loadings was carried out for examining the correlations between social support variables and the extracted factors. In this study, the variables with absolute values greater than 0.70 was set as the selection threshold because these values are stable which exhibit moderate to strong loadings on the extracted factors. After varimax rotation, there were 2 factors with eigenvalues greater than one (Table 1) and they explained approximately $45.79 \%$ (first factor) and $12.85 \%$ (second factor) of the variance respectively.

The eigenvalues with lower than one $(<1.0)$ are neglected because of redundant with more important factors. Table 1 and Fig. 1 highlights that 5 variables are under the dimension of family (SS1, SS2, SS3, SS8 and SS9) and 4 variables under the dimension of friends (SS4, SS5, SS6 and SS7) used in this study satisfy the 0.70 factor loadings threshold. In first factor (family), it has high loadings from 2 variables out of 5 variables which are SS8 (0.796) and SS9 (0.770). This factor can be interpreted as a potential of family sources in social support. In second factor (friend), it exhibits high loading from SS4 (0.730), SS5 (0.851) and SS7 $(0.725)$. 
Table 1. After varimax rotation of social support and quality of index

\begin{tabular}{|c|c|c|c|c|c|c|c|c|c|c|c|c|c|c|c|}
\hline \multirow[b]{3}{*}{ Source } & \multirow{2}{*}{\multicolumn{2}{|c|}{$\begin{array}{l}\text { Original } \\
\text { Sources }\end{array}$}} & \multirow{2}{*}{\multicolumn{2}{|c|}{$\begin{array}{l}\text { Poor } \\
\text { QoLi }\end{array}$}} & \multirow{2}{*}{\multicolumn{3}{|c|}{$\begin{array}{l}\text { Low } \\
\text { QoLi }\end{array}$}} & \multirow{2}{*}{\multicolumn{2}{|c|}{$\begin{array}{c}\text { Moderate } \\
\text { QoLi }\end{array}$}} & \multirow{2}{*}{\multicolumn{3}{|c|}{$\begin{array}{l}\text { Good } \\
\text { QoLi }\end{array}$}} & \multirow{2}{*}{\multicolumn{3}{|c|}{$\begin{array}{c}\text { Excellent } \\
\text { QoLi }\end{array}$}} \\
\hline & & & & & & & & & & & & & & & \\
\hline & D1 & D2 & D1 & D2 & D1 & D2 & D3 & D1 & D2 & D1 & D2 & D3 & D1 & D2 & D3 \\
\hline SS1 & 0.67 & 0.34 & 0.87 & 0.01 & 0.85 & 0.07 & 0.33 & 0.66 & 0.32 & 0.71 & 0.24 & 0.14 & 0.19 & 0.74 & 0.10 \\
\hline $\mathrm{SS} 2$ & 0.68 & 0.38 & 0.87 & 0.07 & 0.74 & 0.21 & 0.16 & 0.69 & 0.37 & 0.88 & 0.11 & 0.10 & 0.26 & 0.77 & 0.16 \\
\hline SS3 & 0.69 & 0.37 & 0.95 & -0.26 & 0.92 & 0.06 & 0.14 & 0.65 & 0.39 & 0.83 & 0.14 & 0.18 & 0.14 & 0.94 & 0.17 \\
\hline $\mathrm{SS} 4$ & 0.25 & 0.73 & 0.19 & 0.67 & 0.35 & 0.72 & 0.30 & 0.20 & 0.66 & 0.17 & 0.75 & 0.20 & 0.76 & 0.30 & 0.14 \\
\hline SS5 & 0.11 & 0.85 & 0.41 & 0.43 & 0.20 & 0.65 & -0.01 & 0.07 & 0.83 & 0.10 & 0.86 & 0.06 & 0.85 & 0.16 & 0.15 \\
\hline SS6 & 0.24 & 0.52 & 0.74 & 0.53 & 0.10 & 0.63 & 0.14 & 0.19 & 0.42 & 0.21 & 0.69 & 0.20 & 0.57 & 0.17 & 0.18 \\
\hline SS7 & 0.21 & 0.73 & 0.78 & 0.37 & -0.10 & 0.75 & 0.20 & 0.16 & 0.68 & 0.26 & 0.59 & 0.13 & 0.77 & 0.18 & 0.23 \\
\hline SS8 & 0.80 & 0.11 & -0.13 & 0.96 & 0.20 & 0.15 & 0.86 & 0.83 & -0.01 & 0.15 & 0.12 & 0.82 & 0.18 & 0.18 & 0.88 \\
\hline SS9 & 0.77 & 0.10 & 0.15 & 0.65 & 0.23 & 0.13 & 0.91 & 0.77 & -0.01 & 0.15 & 0.14 & 0.87 & 0.14 & 0.13 & 0.87 \\
\hline Var. (\%) & 31.09 & 27.53 & 42.55 & 27.33 & 26.33 & 22.19 & 20.71 & 29.98 & 23.94 & 24.05 & 24.93 & 17.80 & 26.49 & 24.9 & 19.07 \\
\hline Cum. (\%) & 31.09 & 58.62 & 42.55 & 69.88 & 26.33 & 48.52 & 69.23 & 29.98 & 53.92 & 24.05 & 48.98 & 66.78 & 26.49 & 51.4 & 70.53 \\
\hline Eigenval. & 4.20 & 1.16 & 4.19 & 2.12 & 3.74 & 1.47 & 1.03 & 3.54 & 1.31 & 3.63 & 1.27 & 1.11 & 4.01 & 1.22 & 1.12 \\
\hline
\end{tabular}

*Strong factor loading $>0.70$ is shown in bold

Note: $\mathrm{SS} 1=$ There is a special person with whom I can share my joys

SS2 $=$ There is a special person with whom I can share my sorrows

SS3 = My family really tries to help me

SS4 = My friends really try to help me

SS5 $=$ I can count on my friends when things go wrong

SS6 $=$ I can talk about my problems with my family

SS7 $=$ I have friends with whom I can share my joys and sorrows

SS8 = I get the emotional help and support I need from my family

SS9 $=$ I have a special person who is a real source of comfort to me 
The factor loadings after Varimax rotation of the Quality of life index for the 9 sources social support generated by FA are given in Table 2. In the poor QoLi, factor 1 explained $42.55 \%$ of the total variance and was dominated by SS1 (0.87), SS2 (0.87) and SS3 (0.95) which indicated that the sources are from family. Meanwhile, factor 2 explained $27.33 \%$ of the total variance and originated from friend. This source was classified based on high factor loadings of SS8 (0.96). In the low QoLi, factor 1 explained $26.33 \%$ of the total variance and originated from family. These components were classified based on high factor loadings of SS1 (0.85) and SS3 (0.92). While factor 2, was classified based on high factor loadings of SS7 (0.75) and factor 3 based high factor loadings of SS8 (0.86) and SS9 (0.91). In the moderate QoLi, factor 1 explained $29.98 \%$ of the total variance and originated from family. This source was classified based on high factor loadings of SS1 (0.83). While factor 2, was classified based on high factor loadings of SS5 (0.83) explained of 23.94\% of the total variance.

In the good QoLi, factor 1 explained $24.05 \%$ of the total variance and originated from family. This source was classified based on high factor loadings of SS2 (0.88) and SS3 (0.83). While, factor 2 was classified based on high factor loadings of SS5 (0.86) explained of $24.93 \%$ of the total variance. Factor 3 originated from SS8 (0.82) and SS9 (0.87). In the excellent QoLi, factor 1 explained $26.49 \%$ of the total variance and originated from family. This source was classified based on high factor loadings of SS3 (0.94). While, factor 2 was classified based on high factor loadings of SS3 (0.94) explained of $24.97 \%$ of the total variance. Factor 3 originated from SS8 (0.88) and SS9 (0.87). SS2 and SS8 appear in all category show the important of the factor. After the major sources were identified for the nine social support variables in the study area, the next step was to determine the contribution of each possible source to the total amount of each social support. 
Table 2. Factor loadings after varimax rotation of the quality of life index for the nine sources social support generated by FA

\begin{tabular}{ccccccc}
\hline & SS/ & SS/ & SS $/$ & SS/ & SS/ & SS/ \\
& QoLi & Excellent & Good & Moderate & Low & Poor \\
& & QoLi & QoLi & QoLi & QoLi & QoLi \\
Observations & 1752 & 345 & 948 & 398 & 51 & 10 \\
R $^{2}$ & 0.244 & 0.043 & 0.075 & 0.042 & 0.054 & 0.509 \\
Adjusted R & 0.240 & 0.037 & 0.073 & 0.037 & 0.014 & 0.369 \\
RMSE & 0.160 & 0.06 & 0.071 & 0.068 & 0.064 & 0.065 \\
\hline
\end{tabular}

To determine the contribution of the identified sources, the MLR statistical approach was then applied. In this study, MLR are used particularly to explain the relationship between the source apportionment generated by FA and their correlation to QoLi values. The quality of life index was calculated from each of the factor of Maqasid Shariah Quality of Life. Other than that, MLR also examines the relationship of each source to the dependent variable (QoLi) with 9 social support factor as independent variables. Sources of contributions were then calculated with FA-MLR to identify main important factor among drug abuse inmates in Malaysia Prison. The coefficient value $\left(\mathrm{R}^{2}\right)$ in each factor was then used to calculate the apportionment of each source to the concentration. Due to the importance of $\mathrm{R}^{2}$, adjusted $\mathrm{R}^{2}$ and RMSE values for better coefficient results, the finding of the study shows that the values of $\mathrm{R}^{2}$, adjusted $\mathrm{R}^{2}$ and RMSE for the original social support-QoLi (9 variables) were 0.244 , 0.240 and 0.160 respectively from the goodness of fit statistics.

The values of $\mathrm{R}^{2}$, adjusted $\mathrm{R}^{2}$ and RMSE for Poor QoLi (2 variables) were 0.509, 0.369 and 0.06 respectively. Followed by the values of $\mathrm{R}^{2}$, adjusted $\mathrm{R}^{2}$ and RMSE for Low QoLi (2 variables) were $0.05,0.01$ and 0.06 respectively. Meanwhile, the values of $\mathrm{R}^{2}$, adjusted $\mathrm{R}^{2}$ and RMSE for Moderate QoLi (2 variables) were 0.04, 0.04 and 0.07. Followed by the values of $\mathrm{R}^{2}$, adjusted $\mathrm{R}^{2}$ and RMSE for Good QoLi (2 variables) were $0.07,0.07$ and 0.07 respectively. Lastly, the values of $\mathrm{R}^{2}$, adjusted $\mathrm{R}^{2}$ and RMSE for Excellent QoLi (2 variables) were 0.07, 0.07 and 0.07 respectively. From the above result, the Poor QoLi shows the highest coefficient of determination $\mathrm{R}^{2}(0.509)$ contributed by the 2 variables. From the finding, poor 
QoLi has been selected as the best due the smallest RMSE and the closest $\mathrm{R}^{2}$ value of 1 when compared among tested variables.

Fig. 2 depicted the bar chart of standardized coefficient of independent variable of the QoLi linear regression model and the contribution for each factor. They allow to directly compare the relative influence of the explanatory variables (SS) on the dependent variable (QoLi) and their significance. The negative standardized coefficient of independent variables (SS5 and SS6) in model a, b and c are based on negatively correlation to QoLi values (as all the independent variable decrease (SS5 and SS6), QoLi value increase.

Fig. 3 represents the residual analysis of the observed and predicted of the total QoLi using the MLR modelling for original QoL indicators. The findings have shown that the deficiency of the model for original QoL indicators, Poor QoL, Low QoL, Moderate QoL, Good QoL and Excellent QoL which the data sets indicate a great difference in the range of -2.5 to $1,-3$ to $2,-3$ to $2,-3$ to 3 and -2 to 3 respectively.

The verification of the model was influenced by the outlier observation as illustrated in Fig.4, which from the actual total QoL indicators indicates that some of observations were out from $95 \%$ of the confidence interval range (lower and upper boundary) especially for the model of Low QoL, Moderate QoL and Excellent QoL but contrast to Poor QoL model. The main objectives of plotting this graph is to prove that the MLR model is suitable to be used for total QoL prediction because it gives the great difference between predicted total QoL and calculated total QoL.

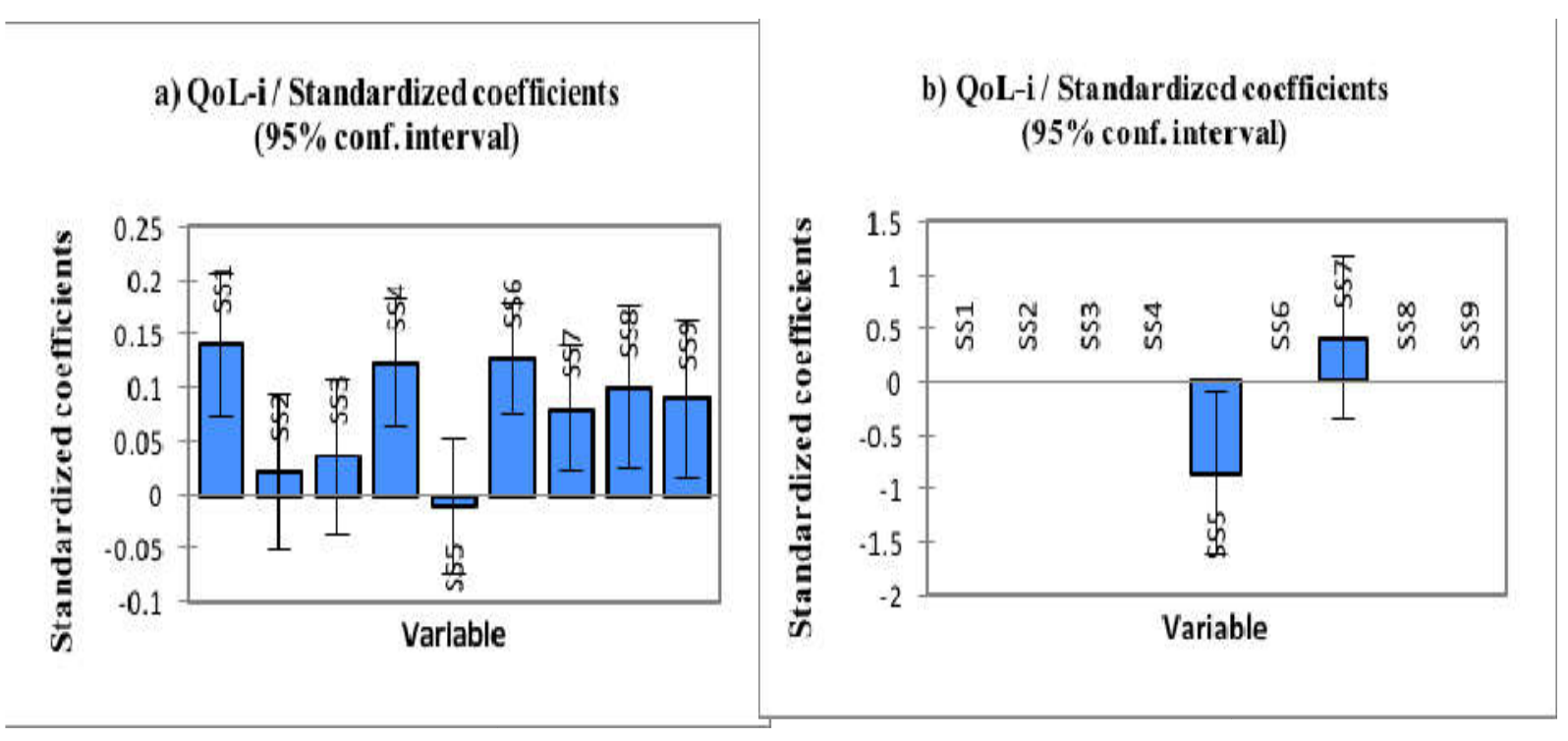


c) Q0L-i / Standar dized coefficients ( $95 \%$ conf. interval)

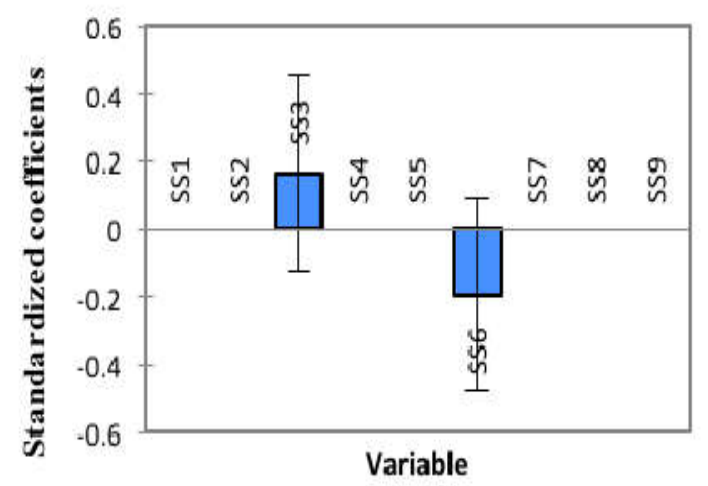

e) QoL-i / Standardize d coefficients ( $95 \%$ conf. interval)

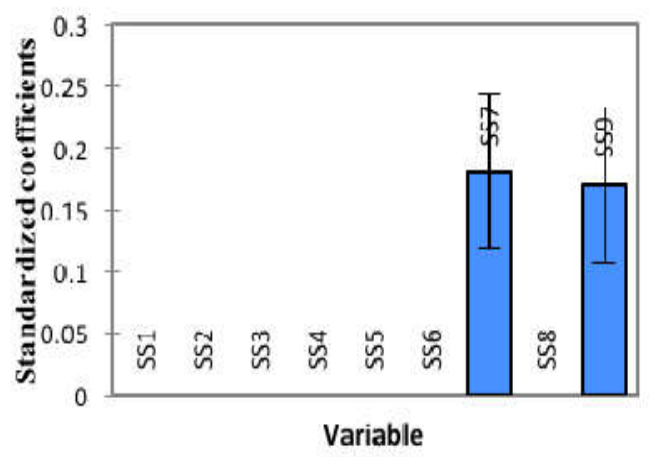

d) QoL-i / Standar dized coefficients ( $95 \%$ conf. interval)

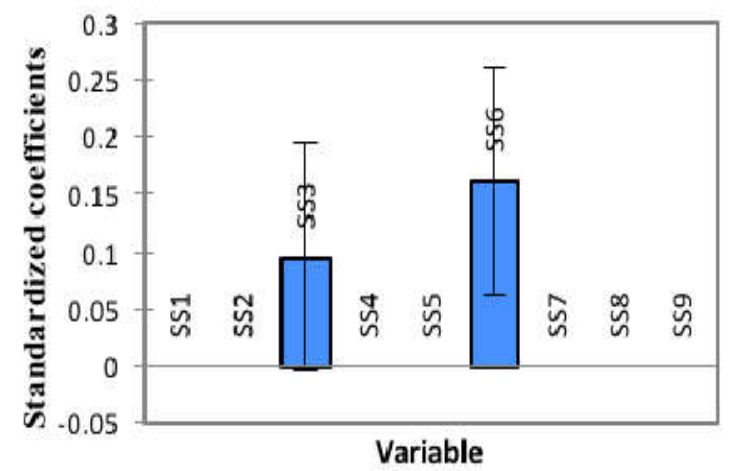

f) QoL-i / Standardized coefficients (95\% conf. interval)

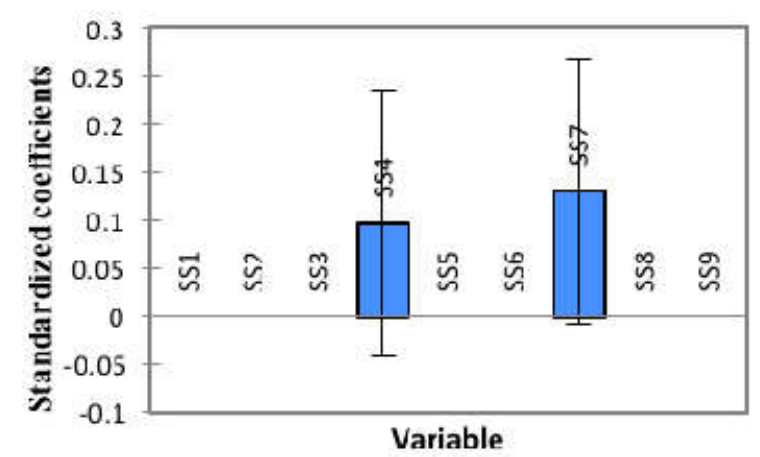

Fig.2. Bar chart of the standardized coefficient for the independent variable: (a) IV of QoLi, (b) IV of Poor QoLi, (c) IV of Low QoLi, (d) IV of moderate QoLi, (e) IV of good QoLi, and (f) IV of excellent QoLi

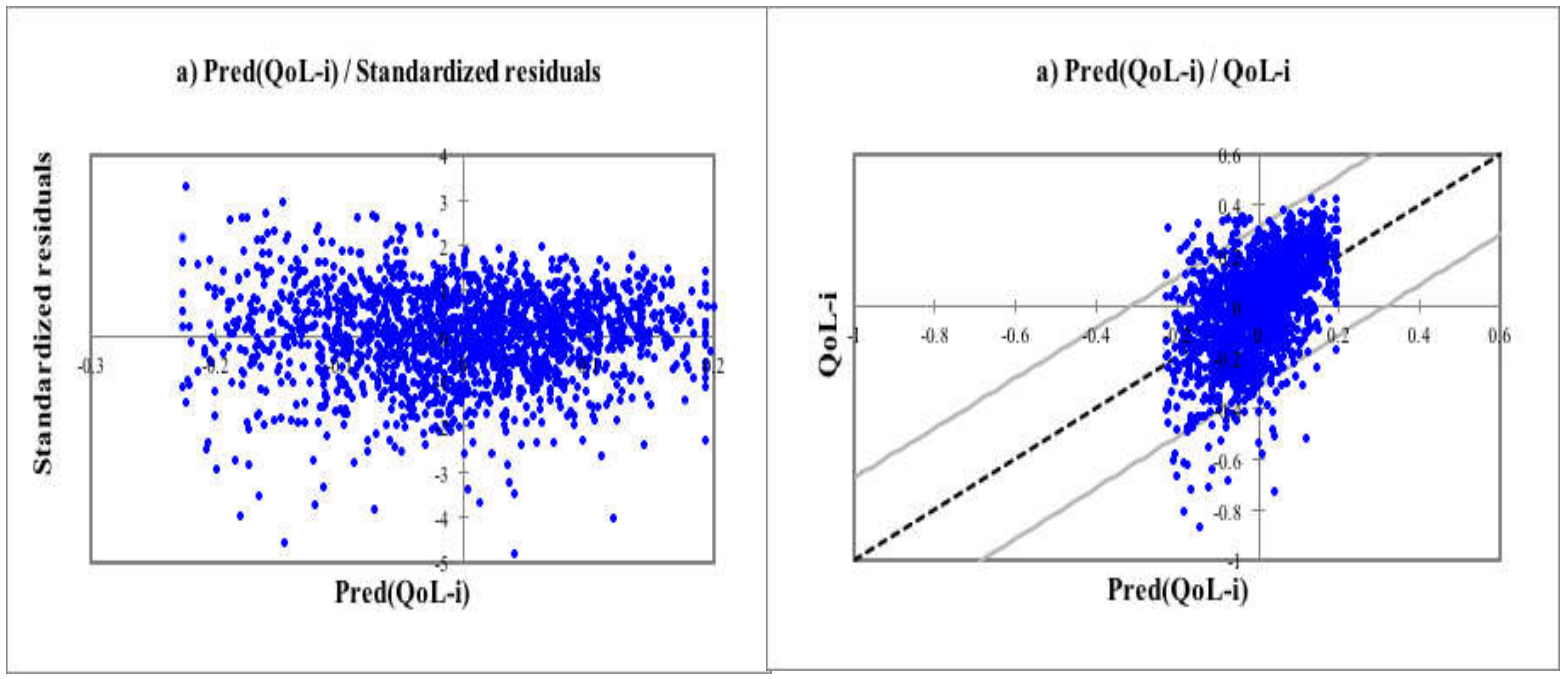




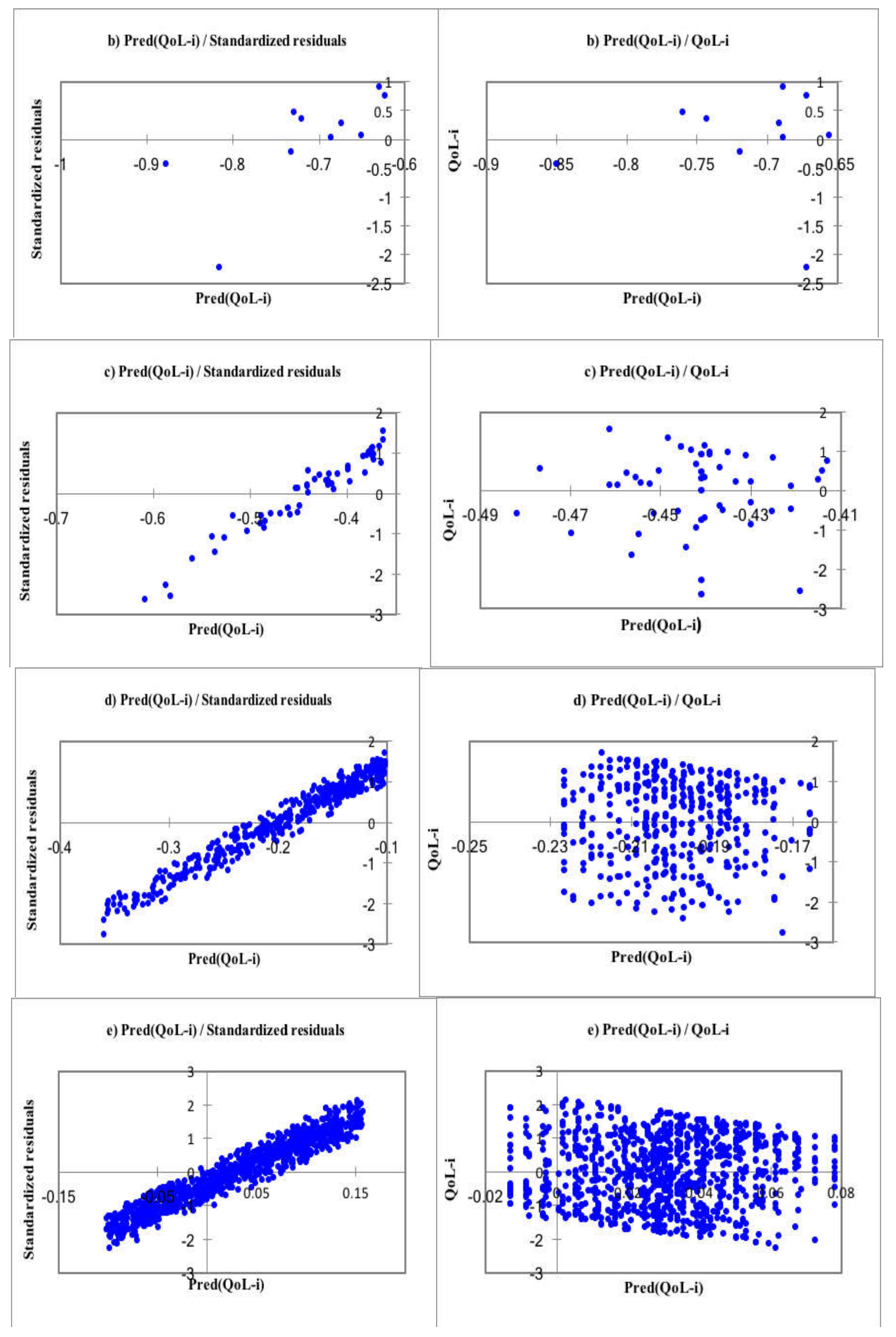




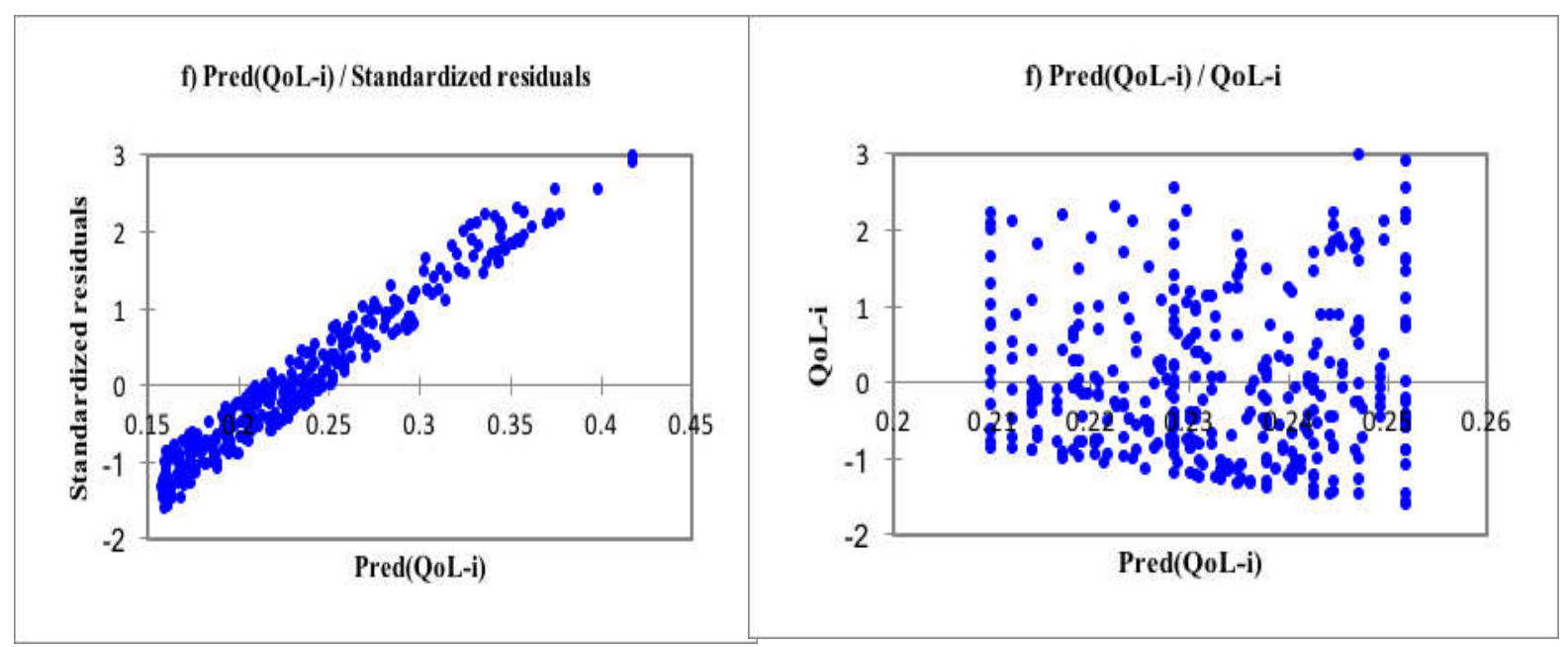

Fig.3. Scatter plot diagram of standardized residual of (Left) actual total QoLi, and (Right) predicted total QoLi for: (d) Moderate QoL indicator model, (e) Good QoL indicator model, (f) Excellent QoL indicator model

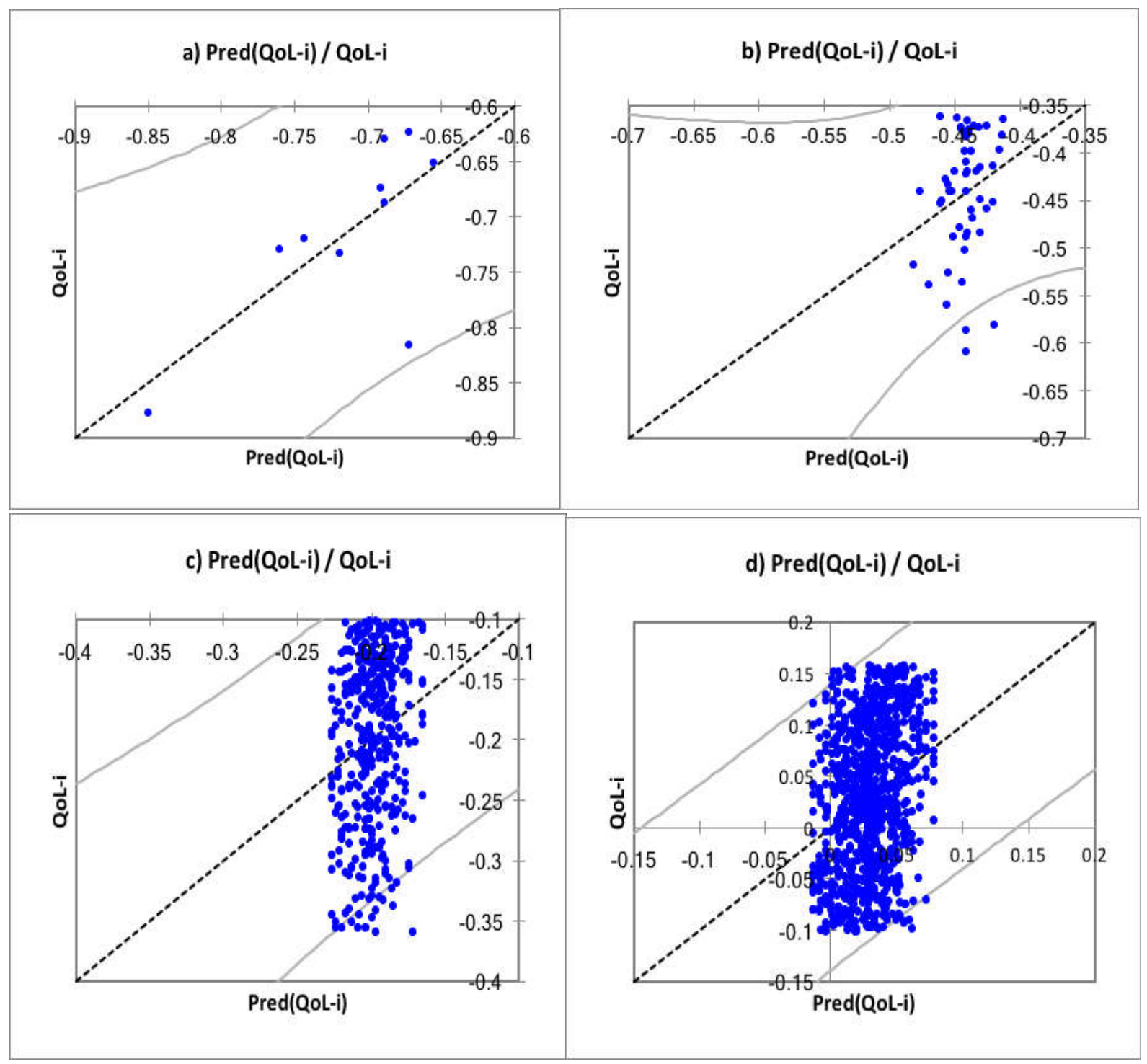




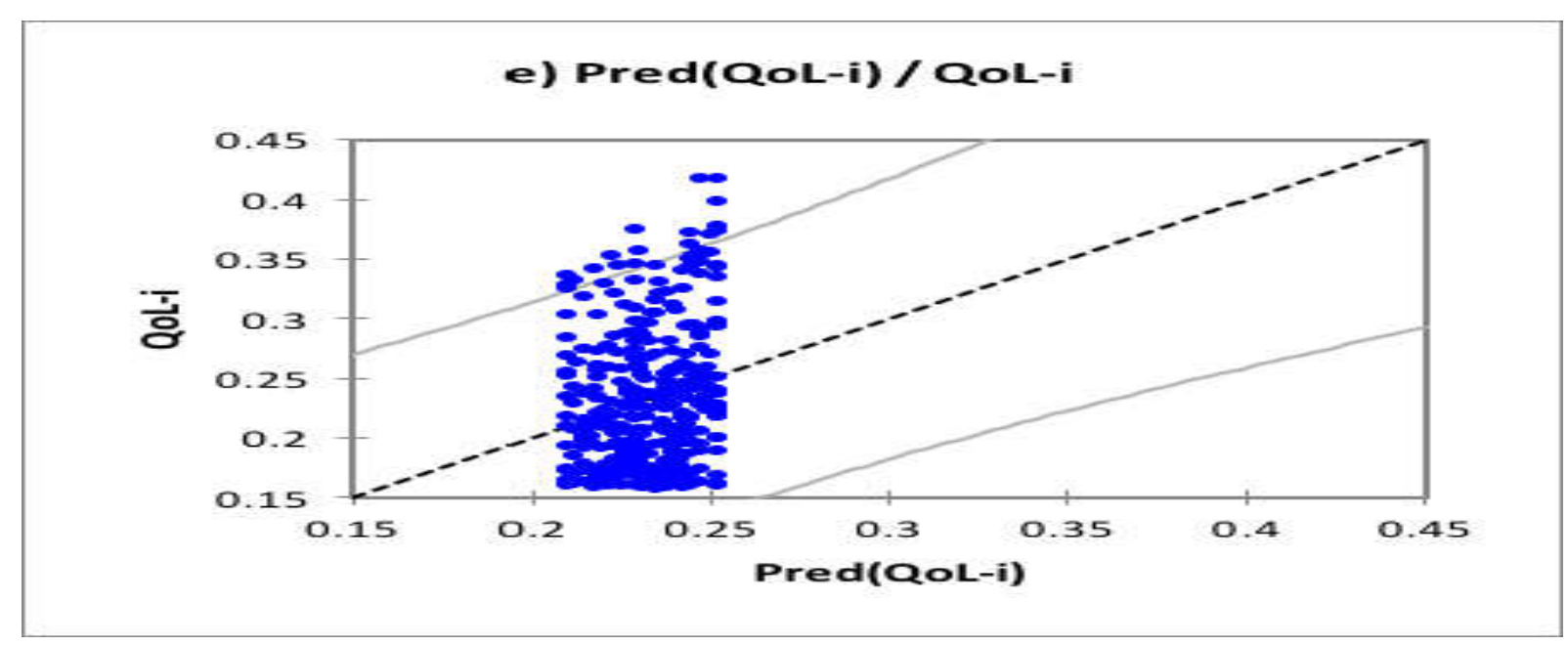

Fig.4. Scatter plot diagram of QoL index (predicted) vs actual total QoL index graph for: (a) original QoL indicator model, (b) Poor QoL indicator model, (c) Low QoL indicator model, (d) Moderate QoL indicator model, (e) Good QoL indicator model, (f) Excellent QoL indicator model

\section{CONCLUSION}

The current study has implications for criminological research. From this study, it can be concluded that the Source Apportionment of Social Support and Quality of Life Index among Drug Abuse Inmates in Malaysian prison were succesfully studied by applying procedures of FA and MLR. To identify the source social support, FA was done. In this study, the sources of variation are expected derived from family, friends and significance others.

Multiple linear regression (MLR) analysis was done to identify the the variability of the proposed equation to predict values of the total QoLi. When comparing from six models developed, the R2 values were found to be strong because they were high and significant at p-value $(<0.05)$. The poor QoLi model shows the highest R2 with the value of 0.509 followed by the Original QoL, High, Low, Excellent, Moderate model with the value of 0.244, 0.075, $0.054,0.043$ and 0.042 respectively. In this study, the finding also shows that the sources from family contributes the most of the total QoLi among drug abuse inmates and this sources can be categorized as the important sources to the prison management to tackle the issue. Beyond that, it became clear that most of the drug abuse inmates reported satisfaction in the social relationships domain, especially those who received support from family members to provide care. 


\section{ACKNOWLEDGEMENTS}

The research is funded by the Niche Research Grant Scheme (NRGS-KPM), UniSZA/NRGS/2013/RR057 Universiti Sultan Zainal Abidin (UniSZA).

\section{REFERENCES}

[1] The Joint United Nations Programme on HIV and AIDS (UNAIDS). Global Aids response progress reporting 2014: Construction of core indicators for monitoring the 2011 United Nations Political Declaration on HIV and AIDS. 2014, http://www.unaids.org/sites/default/files/media_asset/GARPR_2014_guidelines_en_0.pdf

[2] Yuen M, Zahid K Stamp out drug addiction. The Star Online. 2013, http://www.thestar.com.my/News/Nation/2013/06/21/Zahid-Stamp-out-drug addiction.aspx.

[3] Agensi Antidadah Kebangsaan (AADK). Maklumat dadah 2013. 2013, http://www.adk.gov.my/html/laporandadah/2013/Buku\%20Maklumat\%20Dadah\%202013.pdf [4] Diarsvitri W, Iwu D U. Sexuality among senior high school students in Papua and West Papua Provinces, Indonesia. International Journal on Advanced Science, Engineering and Information Technology, 2011, 1(6):702-706

[5] Yusoff F, Shril N., Rasidi N M, Zaki N A M, Muhamad N, Ahmad N. Illicit drug use among school-going adolescents in Malaysia. Asia Pacific Journal of Public Health, 2014, 26(55):100-107

[6] Huong A G W, Guan N C, Nordin A S A, Adlan A S A, Habil H. Quality of life assessment of opioid substance abusers on methadone maintenance therapy (MMT) in University Malaya Medical Center. ASEAN Journal of Psychiatry, 2009, 10(1):1-11

[7] Karim F, Mohamad M, Toriman M E, Salim N A, Muhammad N. The mediating effect of perceived social support on the relationships between quality of life and retention among opioids dependence in methadone maintenance treatment. In 2nd IMT-GT Regional Convention on Drug, Substance and Alcohol Abuse Among Tertiary Institution, 2014 [8] Pedersen P V, Andersen P T, Curtis T. Social relations and experiences of social isolation among socially marginalized people. Journal of Social and Personal Relationships, 2012, 29(6):839-858 
[9] Tariqi R, Tamini B K. Self-regulation and self-concept in students of Islamic Azad University, Saravan Branch, Iran. Europe's Journal of Psychology, 2014, 3(12):83-93

[10] Pettus D C. Social support among releasing men prisoners with lifetime trauma experiences. International Journal of Law and Psychiatry, 2014, 37(5):512-523

[11] D’Ovidio F D, Leogrande D, Mancarella R, Schinzano A, Viola D. A multivariate analysis of the quality of public transport services. Procedia Economics and Finance, 2014, 17:238-247

[12] Ul-Saufie A Z, Yahaya A S, Ramli N A, Rosaida N, Hamid H A. Future daily PM10 concentrations prediction by combining regression models and feedforward backpropagation models with principal component analysis (PCA). Atmospheric Environment, 2013, 77:621-630

[13] Cavanaugh A M, Buehler C. Adolescent loneliness and social anxiety: The role of multiple sources of support. Journal of Social and Personal Relationships, 2016, 33(2):149-170

[14] Talwar P, Kumaraswamy N, Ar M F. Perceived social support, stress and gender differences among university students: A cross sectional study. Malaysian Journal of Psychiatry, 2013, 22(2):42-49

[15] Chang V Y, Bendel T L, Koopman C, McGarvey E L, Canterbury R J. Delinquents' safe sex attitudes relationships with demographics, resilience factors, and substance use. Criminal Justice and Behavior, 2003, 30(2):210-229

[16] Jones S, Cauffman E, Piquero A R. The influence of parental support among incarcerated adolescent offenders the moderating effects of self-control. Criminal Justice and Behavior, 2007, 34(2):229-245

[17] Chang O W, Mutalib A A. Cancer care system: an online support for cancer community. International Journal on Advanced Science, Engineering and Information Technology, 2011, $1(3): 322-326$

[18] Lambert E G, Altheimer I, Hogan N L. Exploring the relationship between social support and job burnout among correctional staff. Criminal Justice and Behavior, 2011, 37(11):1217-1236 
[19] Sippel L M, Pietrzak R H, Charney D S, Mayes L C, Southwick S M. How does social support enhance resilience in the trauma-exposed individual? Ecology and Society, 2015, 20(4):1-10

[20] Cyranowski J M, Zill N, Bode R, Butt Z, Kelly M A, Pilkonis P A, Cella D. Assessing social support, companionship, and distress: National Institute of Health (NIH) toolbox adult social relationship scales. Health Psychology, 2013, 32(3):293-301

[21] Jiang S, Winfree L T. Social support, gender, and inmate adjustment to prison life insights from a national sample. Prison Journal, 2016, 86(1):32-55

[22] Casey S, Day A, Reynolds J. The influence of incarceration length and protection status on perceptions of prison social climate. Criminal Justice and Behavior, 2016, 43(2):285-296

[23] Colvin S J, Hanley M, Flannery D. Victimization, social support, and psychological well-being a study of recently released prisoners. Criminal Justice and Behavior, 2010, 37(10):1140-1159

[24] Mohamad M., Mat A. N. A., Mohamad N., Wan C. W. M. Y., Muhammad N., Karim F. Kualiti hidup pendekatan maqasid Syariah. Terengganu: Universiti Sultan Zainal Abidin Publisher, 2014

[25] Zimet G D, Dahlem N W, Zimet S G, Farley G K. The multidimensional scale of perceived social support. Journal of Personality Assessment, 1988, 52(1):30-41

[26] Thurston G D, Spengler J D. A quantitative assessment of source contributions to inhalable particulate matter pollution in metropolitan Boston. Atmospheric Environment, $1985,19(1): 9-25$

[27] Zaghden H, Kallel M, Elleuch B, Oudot J, Saliot A. Sources and distribution of aliphatic and polyaromatic hydrocarbons in sediments of Sfax, Tunisia, Mediterranean Sea. Marine Chemistry, 2007, 105(1):70-89

[28] Hogarh J N N, Seike Y K, Masunaga S. Atmospheric polychlorinated naphthalenes in Ghana. Environmental Science and Technology, 2012, 46(5):2600-2606

[29] Liu C W, LinK H, Kuo Y M. Application of factor analysis in the assessment of groundwater quality in a Blackfoot disease area in Taiwan. Sci. Science of the Total Environment, 2003, 313(1):77-89 
[30] Lioy P J, Zelenka M P, Cheng M D, Reiss N M, Wilson W E. The effect of sampling duration on the ability to resolve source types using factor analysis. Atmospheric Environment, 1989, 23(1):239-254

[31] Juahir H. Spatial water quality assessment of Langat river basin (Malaysia) using environmetric techniques. Environmental Monitoring and Assessment, 2010, 173(1):625-641

[32] Soares A, Guieysse B, Jefferson B, Cartmell E, Lester J. Nonylphenol in the environment: A critical review on occurrence, fate, toxicity and treatment in wastewaters. Environment International, 2008, 34(7):1033-1049

[33] Azid A, Juahir H, Toriman M E, Kamarudin M K A, Saudi A S M, Hasnam C N C, Aziz N AA, Azaman F, Latif M T, Zainuddin S F M, Osman M R, Yamin M. Prediction of the level of air pollution using principal component analysis and artificial neural network techniques: A case study in Malaysia. Water, Air, and Soil Pollution, 2014, 225(8):1-14

[34] Juahir H, Zain S M,Yusoff M K, Hanidza T I T, Armi A S M, Toriman M E, Mokhtar M. Spatial water quality assessment of Langat River Basin (Malaysia) using chemometric techniques. Environmental Monitoring and Assessment, 2011, 173(1-4):625-641

[35] Wang W C, Chen K S, Chen S J, Lin C C, Tsai J H, Lai C H, Wang S K. Characteristics and receptor modeling of atmospheric PM2. 5 at urban and rural sites in Pingtung, Taiwan. Aerosol and Air Quality Research, 2008, 8(2):112-129

[36] GazzazN M, Yusoff M K, Ramli M F, Aris A Z, Juahir H. Characterization of spatial patterns in river water quality using chemometric pattern recognition techniques. Marine Pollution Bulletin, 2012, 64(4):688-698

\section{How to cite this article:}

Ali NAM, Mohamad M, Juahir H, Kamarudin MKA, Muhammad N, Lee MSMR. Source apportionment of social support and quality of life index among drug abuse inmates using multiple linear regression. J. Fundam. Appl. Sci., 2017, 9(2S), 46-65. 